Jurnal Konstruksi Hukum | ISSN: XXXX | E-ISSN: XXXX

Vol. 1, No. 2, Oktober 2020, Hal. 315-319| Available online at https://www.ejournal.warmadewa.ac.id/index.php/jukonhum

DOI: https://doi.org/10.22225/jkh.1.2.2563.315-319

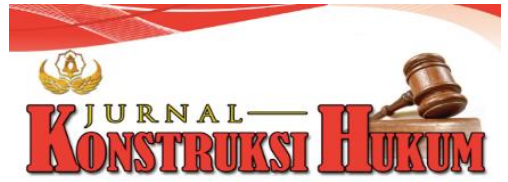

\title{
KEDUDUKAN SUMPAH PEMUTUS DALAM PEMBUKTIAN SENGKETA TANAH WARIS
}

\author{
I Gusti Ayu Maha Patni, I Made Suwitra, I Ketut Sukadana \\ Fakultas Hukum Universitas Warmadewa, Denpasar-Bali, Indonesia
}

\begin{abstract}
Abstrak
Penelitian ini dilatarbelakangi oleh fenomena tentang sengketa tanah waris yang sering terjadi di masyarakat. Ketika pembagian warisan tidak adil maka para ahli waris dapat mengajukan gugatan ke pengadilan sesuai dengan pilihan hukum baik secara hukum perdata barat maupun secara hukum adat. Penelitian ini bertujuan untuk mengetahui prosedur sumpah pemutus dalam sengketa tanah waris dan menganalisis kekuatan pembuktian sumpah pemutus dalam sengketa tanah waris. Penelitian ini menggunakan metode penelitian normatif dengan tujuan menganalisis kekaburan norma mengenai pembuktian sumpah pemutus. Data yang digunakan bersumber dari bahan-bahan hukum seperti peraturan perundang-undangan, Kitab Undang-undang Hukum Perdata, HIR atau RBg dan Yurisprudensi. Hasil analisis menunjukan bahwa prosedur sumpah pemutus dalam sengketa tanah waris yaitu sumpah pemutus (sumpah decisoir) yang dibebankan atas permintaan salah satu pihak kepada lawannya. Jenis sumpah pemutus atau sumpah decisoir dapat berupa sumpah pocong, sumpah mimbar, sumpah klenteng, serta sumpah cor yang dikenal dalam masyarakat Hindu di Bali. Sumpah pemutus dalam sengketa tanah waris yaitu sumpah pemutus yang dilakukan apabila tidak ada upaya pembuktian apapun dalam suatu perkara. Kemudian, kekuatan pembuktian sumpah pemutus dilihat dalam Putusan Nomor 148/PDT.G/2016/PN GIN, bahwa kekuatan pembuktian sumpah pemutus memilki kekuatan memutuskan perkara atau perselisihan dimana memiliki nilai kekuatan pembuktian sempurna, mengikat dan menentukan.
\end{abstract}

Kata Kunci: Sengketa Tanah Waris; Sistem Pembuktian; decisoir

\begin{abstract}
This study is motivated by the phenomenon of inherited land disputes that often occur in the community. When the distribution of inheritance is not fair, the heirs can file a lawsuit in court according to the choice of law, both in western civil law and in customary law. This study aims to determine the procedure for the breaker's oath in inherited land disputes and to analyze the power of proof of the breaker's oath in inherited land disputes. This study uses a normative research method with the aim of analyzing the obscurity of norms regarding the proof of the breaker's oath. The data used comes from legal materials such as statutory regulations, Civil Code and Jurisprudence. The results of the analysis show that the procedure for the breaker's oath in inherited land disputes is the breaker's oath (oath decisoir) which is charged at the request of one party to the opponent. The types of breaking oaths or decisoir oaths can be in the form of pocong oaths, pulpit vows, pagoda oaths, and cast oaths which are known in Hindu society in Bali. An oath of decision making in inherited land disputes, namely an oath of decision made when there is no attempt to prove anything in a case. Then, the power of proof of the breaker's oath is seen in Decision Number 148 / PDT.G / 2016 / PN GIN, that the power of proof of the breaker's oath has the power to decide cases or disputes which have the value of perfect proving power, binding and determining.
\end{abstract}

Keywords: Land Inheritance Dispute; Authentication System; decisoir

\section{PENDAHULUAN}

Negara Indonesia merupakan negara yang memiliki beragam budaya dan adat istiadat. Negara Indonesia memiliki adat istiadat yang bersifat religius yang mengandung unsur religi dalam suatu lingkungan masyarakat tersebut. Sifat magis religius diartikan sebagai suatu pola pikir yang didasarkan pada religiositas, yakni keyakinan masyarakat tentang adanya sesuatu yang bersifat sakral. Sebelum masyarakat hukum adat bersentuhan dengan hukum agama, masyarakat hukum adat membuktikan kebenaran religiusitas ini dengan cara berpikir yang prelogika, animistis, dan kepercayaan kepada alam gaib yang menghuni suatu benda. Selain itu, terdapat hal atau sifat religius atau magis yang dapat berarti sebagai kepercayaan dalam masyarakat yang tidak mengetahui pemisahaan diantara dunia lahir (fakta- 
fakta) dengan dunia gaib (makna-makna yang tertanam atau tersembunyi dibalik fakta tersebut) bahwa keduanya mestinya berjalan selaras.

Beberapa penelitian tentang sumpah pemutus dalam pembuktian alat bukti di pengadilan seperti Kaligis (2017); Malek, Jeniwaty, Sulaiman, \& Harun (2015); Olaofe \& Shittu (2014). Dalam hal ini, masyarakat semestinya berusaha menghindarai maupun mencegah timbulnya disharmoni, yang artinya masyarakat harusnya selalu menumbuh kembangkan dan membina suatu keselarasan, keserasian, dan keseimbangan antara dunia lahir (dunia nyata) dengan dunia batin (dunia gaib) tersebut. Ketidakselarasan atau keseimbangan yang terjadi didalam hubungan antara dunia tersebut berbanding lurus dengan ketidakselarasan atau ketidakseimbangan pada tingkat yang lebih besar, yaitu yang ada dalam alam semesta (makrokosmos) (Suriyaman, 2014). Dengan demikian, tidak dapat dikatakan hal tersebut berlebihan bahwa didalam hukum adat memiliki dua sisi yang saling berdampingan. Pada satu sisi ini, hukum adat dapat dikatakan bersifat tradisional, yang artinya melanjutkan tradisi leluhur, cenderung mempertahankan pola-pola yang sebelumnya telah terbentuk. Sementara pada sisi lainnya, sebagai hukum yang hidup serta berkembang, hukum adat harus selalu mengikuti perkembangan yang terdapat dalam masyarakat.

Hukum adat pun memiliki satu sifat yang terbuka. Artinya hukum adat dapat menerima sistem hukum lain sepanjang masyarakat yang bersangkutan menganggap bahwa sistem hukum lain (asing) tersebut patut atau berkesesuaian. Perkembangan sifat ini terjadi sebagai hasil interaksi harmonis antara sistem-sistem hukum yang berlaku dalam masyarakat Indonesia, yaitu antara hukum tertulis dengan hukum yang tidak tertulis atau diantara hukum adat dengan hukum Islam dan hukum Barat yang ada sekarang dipertahankan melalui kekuasaan suatu lembaga peradilan.

Dalam kehidupan bermasyarakat tidak terlepas dari proses interaksi antar masyarakat yang satu dengan lain, baik antar individu maupun kelompok. Dengan demikian juga tidak dapat terlepas dari suatu konflik maupun perselisihan. Salah satu konflik atau perselisihan yang sering terjadi dimasyarakat maupun dalam suatu keluarga yaitu konflik atau sengketa tanah waris. Sengketa tanah terjadi apabila salah satu pihak merasa haknya dirampas oleh orang yang bukan seharusnya mendapatkan hak tersebut ataupun dalam pembagian harta waris dirasa tidak adil oleh para ahli waris itu sendiri.

Hukum kewarisan merupakan suatu hukum harta kekayaan dalam sebuah keluarga, yang dikarenakan wafatnya seseorang, maka terjadilah pemindahan harta kekayaan yang telah ditinggalkan. Dalam hukum kewarisan tersebut mengatur mengenai siapa ahli waris yang berhak mewarisi peninggalan harta kekayaan atau warisan, kedudukan ahli waris, serta perolehan masing-masing ahli waris secara adil.

Sengketa tanah waris terjadi apabila salah seorang mengakui hak orang lain atau pembagian harta warisan dirasa tidak adil, penggunaan jenis hukum yang ada diserahkan kepada pihak-pihak yang bersengketa. Dalam penyelesaian sengketa tanah waris yang terdapat dimasyarakat ataupun dalam keluarga, dilakukan melalui musyawarah diantara ahli waris. Tetapi, apabila timbul atau terjadi pembagian warisan yang tidak dapat diselesaikan dengan cara musyawarah tersebut, para ahli waris dapat mengajukan gugatan ke pengadilan sesuai dengan pilihan hukum, baik dalam hukum perdata barat maupun hukum adat. Namun, apabila dalam sengketa tersebut para pihak tidak memiliki cukup alat bukti dalam melakukan pembuktian atas sengketa tersebut, maka para pihak dapat menggunakan pembuktian dengan sumpah pemutus yaitu untuk membuktikan hak-hak dari para pihak tersebut. Berdasarkan latar belakang tersebut, maka penelitian ini bertujuan untuk mengetahui prosedur sumpah pemutus dalam sengketa tanah waris dan untuk mengetahui kekuatan pembuktian sumpah pemutus dalam sengketa tanah waris.

\section{METODE PENELITIAN}

Penelitian ini merupakan penelitian normative. Pendekatan masalah yang di gunakan yaitu pendekatan perundang-undangan dan pendekatan kasus. Pendekatan perundang-undangan dipilih karena terkait dengan pembuktian sumpah terutama dalam Kitab Undang-undang Hukum Perdata, HIR atau Rbg. Sedangkan, pendekatan kasus beranjak dari pandangan-pandangan dan doktrin-doktrin yang berkembang di dalam ilmu hukum. Pandangan doktrin dapat memperjelas mengenai ide-ide dengan memberikan pengertian-pengertian hukum, konsep-konsep hukum, maupun asas hukum yang relevan dengan permasalahan hukum.

Pembahasan terhadap permasalahan yang diajukan, kemudian ditelaah mulai dari peraturanperaturan yang ada atau yang sedang berlaku dengan konsep berkaitan dengan kekuatan pembuktian 
sumpah pemutus didalam sengketa tanah waris. Adapun sumber data atau bahan hukum yang digunakan yaitu bahan hukum primer seperti peraturan perundang-undangan, meliputi Kitab Undang-undang Hukum Perdata, HIR atau RBg dan Yurisprudensi. Bahan hukum sekunder yaitu bahan hukum bahan yang dapat memberikan penjelasan mengenai bahan hukum primer seperti jurnal hukum, hasil-hasil penelitian atau pendapat pakar hukumyaitu meliputi doktrin, dan hasil-hasil penelitian (Amiruddin \& Asikin, 2004).

Teknik pengumpulan bahan hukum ini adalah dilakukan dengan teknik pengumpulan bahan hukum yaitu yang diperoleh melalui bahan hukum primer yaitu dokumen mengutip dari pasal-pasal yang berkaitan dengan permasalahan yang dikaji. Serta bahan hukum sekunder yaitu melalui pencatatan. Teknik pengumpulan bahan hukum yang digunakan dalam penulisan ini adalah teknik dengan dokumentasi dan pencatatan bahan hukum yang diperlukan yang sesuai dengan pokok permasalahan dari buku-buku literatur.

\section{HASIL DAN PEMBAHASAN}

\section{Prosedur Sumpah Pemutus dalam Sengketa Tanah Waris}

Sumpah pada umumnya adalah merupakan suatu pernyataan yang amat khidmat yang diucapkan ataupun diberikan pada waktu memberi janji atau keterangan dengan mengingat akan sifat mahakuasa daripada Tuhan, dan percaya bahwa siapa saja yang memberi keterangan atau janji yang tidak benar akan dihukum olehNya. Jadi pada hakekatnya sumpah merupakan tindakan yang bersifat religius yang digunakan dalam peradilan (Sudikno, 2002).

Sumpah decisoir atau pemutus adalah sumpah yang dibebankan atas permintaan salah satu pihak kepada lawannya. Pihak yang minta lawannya mengucapkan sumpah disebut deferent, sedangkan pihak yang harus bersumpah disebut delaat (Sudikno, 2002). Sumpah pemutus atau yang menentukan (decissoire eed) diatur dalam Pasal 156 HIR atau 183 Rbg yang menyatakan:

Apabila tidak ada keterangan atau alat bukti lain maka untuk meneguhkan tuntutannya, salah satu pihak dapat meminta kepada lawannya untuk bersumpah di persidangan supaya dengan sumpah itu perkara dapat diputus asalkan sumpah itu mengenai perbuatan yang dilakukan sendiri oleh pihak yang disuruh bersumpah (Elizabeth, 2015).

Pasal 1930 Kitab Undang-Undang Hukum Perdata menyatakan bahwa:

Sumpah pemutus dapat diperintahkan dalam persengketaan apapun, kecuali dalam hal kedua belah pihak tidak mengadakan suatu perdamaian atau dalam hal pengakuan mereka tidak boleh diperhatikan. Sumpah pemutus dapat diperintahkan pada setiap tingkatan perkara, bahkan dalam hal tidak ada upaya pembuktian apapun untuk membuktikan tuntutan atau tangkisan yang memerlukan pengambilan sumpah itu.

Dalam hukum acara perdata dikenal pembuktian dengan sumpah pemutus baik dalam perkara perdata khususnya dalam sengketa tanah waris. Contohnya, dalam soal warisan Penggugat mengajukan gugatan terhadap Tergugat bahwa harta warisan bekum dibagi dan ia menuntut bagiannya. Pihak Tergugat mengatakan itu tidak benar karena harta warisan sudah dibagi. Dalam hal ini Tergugat dibebankan pembuktian bahwa harta warisan tersebut sudah dibagi. Jika Penggugat dibebankan untuk membuktikan secara negatif bahwa harta warisan tersebut belum dibagi, maka akan sangat berat baginya.

Menurut yurisprudensi Mahkamah Agung No. 575 K/Sip/1973, menyatakan bahwa permohonan sumpah decisoir hanya dapat dikabulkan kalau dalam suatu perkara sama sekali tidak terdapat buktibukti. Dalam Putusan Nomor 148/PDT.G/2016/PN GIN. Menjelaskan bahwa dalam sengketa tanah waris ini yaitu dalam membuktikan dalil-dalil gugatan maupun dalam membuktikan bantahannya, penggugat maupun tergugat ternyata tidak mengajukan alat bukti dalam perkara ini baik surat-surat bukti maupun bukti saksi-saksi. Bahwa dalam persidangan Penggugat ternyata mengajukan permohonan sumpah pemutus tertanggal 04 Januari 2017, yang pada pokoknya meminta tergugat untuk bersumpah cor dan atas permohonan tersebut tergugat menyatakan menyanggupi untuk disumpah. Dengan demikian, maka keberadaan sumpah pemutus dalam sengketa tanah waris yaitu bahwa terguggat dibebankan pembuktian sumpah pemutus dalam membuktikan suatu hak atau peristiwa yang dianggapnya benar.

\section{Kekuatan Pembuktian Sumpah Pemutus dalam Sengketa Tanah Waris}

Pembuktian adalah ketentuan-ketentuan yang berisi penggarisan dan pedoman tentang cara-cara yang dibenarkan undang-undang membuktikan kesalahan yang didakwakan kepada terdakwa (Imron \& 
Iqbal, 2019:3). Pembuktian dalam hukum acara perdata, menyisakan persoalan-persoalan yang bersentuhan dengan kepastian dan keadilan, dalam proses pemenuhannya. Maka sebagai bangsa yang merdeka hal tentang pembuktian dan kepastian di wilayah hukum privat, dan selalu menghindar jalur belakang dalam jalan yang ditempuh, serta tetap berdasarkan pada keadilan atas dasar Ketuhanan Yang Maha Esa (Syaiful, 2018).

Dengan demikian apabila dalam mengajukan gugatan, penggugat tidak mengajukan alat bukti apapun, maka dengan ini pembuktian sumpah pemutus dilakukan, karena sumpah pemutus dapat dijadikan alat bukti apabila tidak ada upaya pembuktian lain, sehingga dilihat dari indikator pembuktian sumpah pemutus dalam sengketa tanah waris yaitu bahwa sengketa tanah waris sering terjadi dalam sebuah keluarga dimana sengketa terjadi apabila dalam pembagian harta warisan dirasa tidak adil sehingga menyebabkan salah satu pihak mengajukan gugatan ke pengadilan namun tidak memiliki cukup alat bukti yang kuat, untuk itu penggugat mengajukan pembuktian sumpah pemutus, bahwa sumpah pemutus ini adalah senjata terakhir untuk membuktikan hak yang dikemukakan itu. Tetapi tidak boleh sembarangan dalam mengajukan pembuktian sumpah pemutus ini, apabila mengucapkan sumpah palsu maka diyakini akan mendapatkan hukuman dari Tuhan.

Dalam perkara Nomor 148/PDT.G/2016/PN GIN. Penggugat d melawan Tergugat mengenai perkara sengketa tanah warisan, yang di periksa oleh Pengadilan Negeri Gianyar, tergugat dibebani dengan sumpah pemutus atau sumpah cor sesuai agama Hindu. Sumpah cor sebagai sumpah pemutus ini diajukan penggugat karena tiadanya alat bukti dalam persidangan kasusnya di Pengadilan Negeri Gianyar.

Dalam perkara Nomor 148/PDT.G/2016/PN.GIN, Penggugat mendaililkan bahwa objek sengketa berupa tanah seluas 32 are di Subak Bandung Kawan adalah harta peninggalan kakek mereka yang belum di bagi waris. Pada tahun 2001, objek sengketa tersebut disertifikati oleh kakak kandungnya, Tergugat Bmenjadi atas namanya. Maka, Penggugat pun melakukan gugatan ke pengadilan. Dalam gugatannya, Penggugat meminta agar tergugat dinyatakan telah melakukan perbuatan melawan hukum. Atas semua dalil yang diajukan Penggugat tersebut, Tergugat menyangkal dengan menyatakan objek tanah sengketa adalah miliknya. Kasus ini pun bergulir di meja hukum. Sumpah pemutus atau sumpah cor ini diajukan dalam persidangan, karena tidak ada alat bukti apapun, baik surat maupun saksi dari pihak-pihak yang berperkara. Sumpah cor ini dilakukan untuk mengakhiri semuanya persoalan sengketa.

Dengan demikian, kekuatan pembuktian sumpah pemutus dapat dikatakan sebagai kekuatan pembuktian yang mengikat dimana dalam suatu perkara acap kali hakim memiliki keraguan atas alatalat bukti yang diajukan oleh penggugat maupun tergugat. Maka kemudian hakim memerintahkan salah satu pihak mengucapkan sumpah pemutus. Sumpah pemutus (decisoir) mempunyai daya bukti mengikat, oleh karenanya hakim wajib untuk menyesuaikan keputusannya dengan pembuktian tersebut (Syaiful, 2018).

Dalam Putusan Nomor 148/PDT.G/2016/PN GIN menjelaskan bahwa sumpah pemutus memiliki kekuatan untuk memutuskan perkara atau mengakhiri perselisihan sehingga sumpah pemutus mengandung unsur litis decisoir yang dapat mengakhiri proses pemeriksaan perkara yang diikuti pengambilan dan menjatuhkan putusan berdasarkan ikrar sumpah yang diucapkan serta UndangUndang melekatkan pada sumpah pemutus tersebut mempunyai nilai kekuatan pembuktian sempurna, mengikat dan menentukan.

\section{SIMPULAN DAN SARAN Simpulan}

Prosedur sumpah pemutus dalam sengketa tanah waris yaitu bahwa sumpah pemutus atau sumpah decisoir adalah sumpah yang dibebankan atas permintaan salah satu pihak kepada lawannya. Jenis sumpah pemutus atau sumpah decisoir dapat berupa sumpah pocong, sumpah mimbar, sumpah klenteng, serta sumpah cor yang dikenal dalam masyarakat Hindu di Bali. Sumpah pemutus dalam sengketa tanah waris yaitu bahwa sumpah pemutus dapat dilakukan apabila memang tiada upaya pembuktian apapun dalam suatu perkara. Kemudian, kekuatan pembuktian sumpah pemutus ini dilihat dalam Putusan Nomor 148/PDT.G/2016/PN GIN, bahwa kekuatan pembuktian sumpah pemutus memilki kekuatan memutuskan perkara atau perselisihan dimana memiliki nilai kekuatan pembuktian sempurna, mengikat dan menentukan. 


\section{Saran}

Berdasarkan simpulan di atas, dapat disarankan kepada para pihak yang bersengketa dalam melakukan pembuktian sumpah pemutus ini harus sesuai dengan hal yang benar dan bukan dengan melakukan sumpah palsu hanya untuk kepentingan materi belaka. Dalam hal kekuatan sumpah pemutus dapat disarankan kepada hakim agar tidak hanya menilai pembuktian sumpah pemutus tersebut hanya berdasarkan keyakinan hakim saja, melainkan dapat juga dilakukan suatu test kebohongan seperti dalam proses penyidikan pidana. Hal itu penting untuk diketahui apakah tersangka berbohong atau tidak. Sama halnya dengan sumpah pemutus ini, walaupun dilakukan dengan upacara dan di tempat ibadah sekalipun, namun test kebohongan sangat membantu meyakinkan hakim dalam memutus perkara.

\section{DAFTAR PUSTAKA}

Amiruddin, \& Asikin, Z. (2004). Pengantar Metode Penelitian Hukum. Jakarta: Raja Grafindo Persada.

Elizabeth, N. (2015). Hukum Pembuktian Analisis Terhadap Kemandirian Hakim Sebagai Penegak Hukum Dalam Proses Pembuktian. Medan: CV Nuansa Aulia.

Imron, A., \& Iqbal, M. (2019). Hukum Pembuktian. (A. D. Harapan \& Suhendra, Eds.). Tangerang Selatan: UNPAM Press.

Kaligis, R. Y. J. (2017). Penggunaan Alat Bukti Sumpah Pemutus (Decisoir) dalam Proses Pemeriksaan Perkara Perdata di Pengadilan Menurut Teori dan Praktek. Jurnal Hukum Unsrat, 23(8), 1-14.

Malek, M. S. M. A., Jeniwaty, M. J., Sulaiman, M., \& Harun, S. M. (2015). In the Purview of an Oath from the Jurisprudential Method of Islamic Law of Evidence. In R. Omar, H. Bahrom, \& G. de Mello (Eds.), Islamic Perspectives Relating to Business, Arts, Culture and Communication. Singapore: Springer.

Olaofe, M. A., \& Shittu, A. B. (2014). Oath and its Implications from Islamic Perspective. Allawh Journal of Arabic and Islamic Studies, 4(1), 191-202.

Sudikno, M. (2002). Hukum Acara Perdata Indonesia. Yogyakarta: Liberty.

Suriyaman, M. (2014). Hukum Adat, Dahulu, Kini dan Akan Datang. Jakarta: Prenadamedia Group.

Syaiful, B. (2018). Dinamika Hukum Pembuktian dalam Capaian Keadilan (I). Jakarta: Rajawali Pers.

Nusa Bali,"Tiada Bukti Kepemilikan, Tergugat Disumpah Cor di Pura Ulun Kulkul", NusaBali.com, January 2017, p.1, accessed on 11 November 2018 at 21.30 WITA.

http://www.gresnews.com/berita/tips/81539-penyelesaian-sengketa-tanah-warisan/accessed on 29 October 2018 at 19.40 WITA.

Kitab Undang-Undang Hukum Perdata

HIR (Herzein Inlandsch Reglement)

$\mathrm{RBg}$ (Rechtreglement voor de Buitengeweten)

Yurisprudensi Mahkamah Agung No. 575 K/Sip/1973

Putusan Nomor 148/PDT.G/2016/PN GIN. 